\title{
Malaria from hyperendemicity to elimination in Hekou County on China- Vietnam border: an ecological study
}

\author{
Jian-Wei Xu ${ }^{1}$, Jian-Jie Li ${ }^{2}$, Hong-Ping Guo², Shu-Wei Pu², Shu-Mei Li ${ }^{3}$, Rong-Hua Wang ${ }^{3}$, Hui Liu* \\ and Wei-Jia Wang ${ }^{2}$
}

\begin{abstract}
Background: Malaria control and elimination are challenged by diversity and complexity of the determinants on the international border in the Great Mekong Sub-region. Hekou, a Chinese county on the China-Vietnam border, was used to document Chinese experiences and lessons for malaria control and elimination.

Methods: The design was an ecological study. Malaria burden before 1951 and procedures of 64 years (1952-2015) from malaria hyperendemicity to elimination are described. Single and bilinear regression analysis was utilized to analyse the relationship between the annual malaria incidence (AMI) and gross domestic product (GDP), urbanization rate, and banana planting area (BPA).

Results: There was a huge malaria burden before 1951. AMI was reduced from 358.62 per 1000 person-years in 1953 to 5.69 per 1000 person-years in 1960. A system of primary health services, comprising three levels of county township hospitals and village health stations maintained malaria control and surveillance activities in changing political and social-economic settings. However, potential under-reported of malaria and market-oriented healthcare led to a malaria epidemic in 1987. Strong political commitment reoriented malaria from a control to an elimination programme. High coverage of malaria intervention and population access to intervention was crucial for malaria control and elimination; meanwhile, AMI was closely associated with socio-economic development, correlation coefficients (R) $-0.6845(95 \% \mathrm{Cl}-0.7978,-0.6845)$ for national GDP, $-0.7014(-0.8093,-0.7014)$ for national urbanization rate and $-0.5563(-0.7147,-0.3437)$ for BPA.
\end{abstract}

Conclusions: Multifactor, including political commitment, effective interventions, social and economic development and changing ecological environment, and the complicated interactions between these factors contribute to malaria elimination in Hekou County.

\section{Background}

Malaria is a parasitic disease that is transmitted by female Anopheles mosquitoes [1]. About 214 million (range 149-303 million) new cases of malaria occurred worldwide in 2015 [2]. Now, an ambitious new goal has been set by the World Health Organization (WHO) to reduce the global malaria burden by $90 \%$ by 2030 [1], and to

\footnotetext{
*Correspondence: liubible@126.com

${ }^{1}$ Yunnan Institute of Parasitic Diseases, Yunnan Provincial Centre

of Malaria Research, Yunnan Provincial Key Laboratory of Vector-borne

Diseases Control and Research, Puer 665000, China

Full list of author information is available at the end of the article
}

eliminate malaria by 2030 , as well as to eliminate falciparum malaria by 2025 in all countries of Greater Mekong Sub-region (GMS) [3]. Malaria is closely correlated between any two countries such as China and Myanmar along their common border $[4,5]$. Control and elimination of malaria are challenged by diversity and complexity of the determinants in the GMS [6,7], especially on the international border $[6,7]$. Malaria movement across international borders is one of the major obstacles to malaria elimination [8-10].

Hekou County was a malaria hyperendemic areas on the China-Vietnam border. Malaria had ever been the 
most life-health-threaten diseases historically in this region. Socio-economic and environmental characteristics have changed greatly, and malaria is from hyperendemicity to elimination from 1952 to 2015 [11]. Now it is the first county to achieve malaria elimination its international border in southern China, and its achievement was certified by Yunnan Province on 4 November, 2015. Although nowadays the Chinese National Malaria Elimination Action is stable and moving forward [12, 13], related experiences and lessons are not well documented and reported. This paper describes the malaria burden before 1951 and the 64-year period (1952-2015) of procedures, from malaria hyperendemicity to elimination, analyses the impact of political commitment, interventions, social economic development, and ecological environment, on malaria and then discusses experiences and lessons learnt from global malaria eradication.

\section{Methods}

\section{Study site}

The study was carried out in Hekou County $\left(103^{\circ} 23^{\prime}-\right.$ $104^{\circ} 17^{\prime} \mathrm{E}, 22^{\circ} 30^{\prime}-23^{\circ} 02^{\prime} \mathrm{S}$; altitude from 76.4 to $2354.1 \mathrm{~m}$ ), which is located at Red River Valley, southeast of Yunnan Province, China, and shares a border of $193 \mathrm{~km}$ with Vietnam (Fig. 1). The county has a population of 104,609 people (2010) living in an area of $1332 \mathrm{~km}^{2}$, with a tropical monsoon rainforest climate and an annual mean temperature of $23.0{ }^{\circ} \mathrm{C}$ [14]. Anopheles minimus is the primary malaria vector $[15,16]$. Indigenous malaria transmission was interrupted at Hekou County in 2011, and it passed the provincial elimination assessment in 4 November, 2015.

\section{Study design}

The study design was an ecological study. Malaria burden before 1951 and the 64-year dynamics (1952-2015) from malaria hyperendemicity to elimination are described. Association between malaria incidence and socio-economic development and environmental change are analysed by single and bilinear regression.

\section{Data resource and collection}

All available paper records related to malaria surveillance and control activities were reviewed at Hekou County Centre for Disease Control and Prevention (CDC) for collecting data of malaria cases and intervention activities from 1952 to 2007. Chinese Information System for Disease Control and Prevention (CISDCP) began to cover all counties of China from 2008 [17], thus, data on malaria cases and intervention from 2008-2015 were obtained from CISDCP. National and provincial gross domestic product (GDP) and urbanization rate came from the website of the
National Bureau of Statistics of the People's Republic of China. Banana planting area (BPA) was from paper records of Hekou County Bureau of Statistics. Qualitative data was collected by semi-structured, in-depth interviews (SDI) with senior malaria control staff who had worked at Hekou County CDC, Honghe Prefecture CDC and Yunnan Institute of Parasitic Diseases (YIPD) $[18,19]$. In addition, almost all available literature on political, social and economic development, the malaria situation and control related to Hekou County were also reviewed.

\section{Data analysis}

Before 2010, species of malaria parasites were not registered clearly. A combination of clinical symptoms and results of presumptive treatment with anti-malarial drugs were some of the definitions for malaria cases at that time. In the study, annual malaria incidence (AMI) was used to replace annual parasite incidence as the outcome variable, so the AMI included both microscopy confirmed cases and cured cases by presumptive treatment. The amount and impact of intervention activities were described for each stage in the process from hyperendemicity to elimination, although the quantitative relationship between AMI and intervention activities was not done because of unavailability of sequential data. In linear regression analysis, independent variables for social and economic development were national GDP in billions of China Yuan (CNY) and urbanization rate (\%). In Hekou County, banana growing is major part of the economy, which has changed the environment in terms of malaria transmission. Transition from paddy field to banana plantation reduces breeding sites for mosquito larvae, and insecticides used in growing bananas kills mosquitoes. In this reason, BPA (hectares) was used as an independent variable for environmental changes (Fig. 2). In order to obtain a more normal distribution of data, all outcome and independent variables were transformed into common logarithms, and then a linear regression analysis was used to analyse relationships of AMI respectively with GDP, urbanization rate, and BPA from 1952 to 2013 [20]. The number of malaria cases during 20142015 was zero, so data of the 2 years could not be taken into the analysis model. The rapid development of society and economy has improved health information system and reduced the data bias from 2000 to 2015, so the analysis model was conducted for years 2000-2013 again. In order to learn the impact of socio-economic development and environmental change, a bilinear regression analysis was conducted to on AMI association with national GDP and BPA, and with urbanization rate and BPA for years 2000-2013 [20]. 


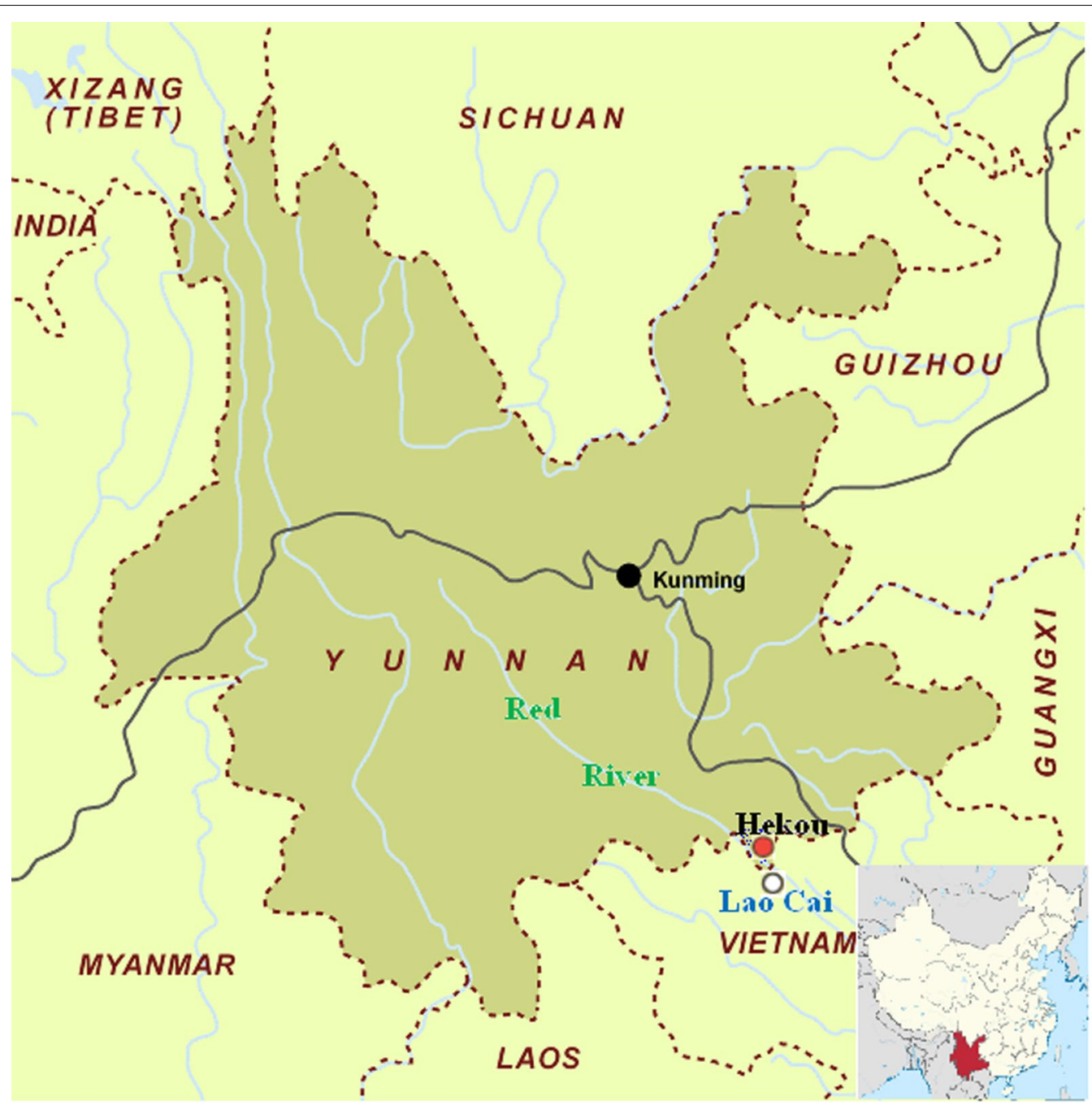

Fig. 1 Map of the study site and neighbouring region

\section{Results}

Malaria burden and interventions, 1901-1951

A formal health service system for malaria surveillance and control in China was not available before 1951. Despite significant differences from different data sources, e.g., the number of deaths from malaria as 12,000 in the report from the French Indo-China Railway Construction Company, to 60,000-70,000 in Chinese literature during the period of the Yunnan railway construction, these records indicated a large number of deaths and frequent outbreaks in Hekou County (Table 1). In 1939, Yunnan Commission of Malaria Control and six Provincial Institutes for Malaria Control (PIMC) were established in the Province, and PIMC 6 was allocated in Hekou County. PIMC 6 organized outreach teams visiting communities to treat malaria, promote use of bed nets, and treat mosquito larvae breeding sites with emerald green (copper acetoarsenit). However, these interventions were terminated because of Japanese military invasion to Yunnan in 1942.

\section{Interventions and incidence, 1952-2009}

1952-1962 Malaria investigation and control activities were initiated in 1952. According to results of SDI from former senior malaria control staff, a malaria control station (MCS) was established to recruit and train health staff in early 1952, and then a malaria control structure comprised of technical officers from military medicine departments and health sector of central and local governments, community health staff (CHWs) and village malaria control workers (VMCWs) was created. The leaders were political officers 

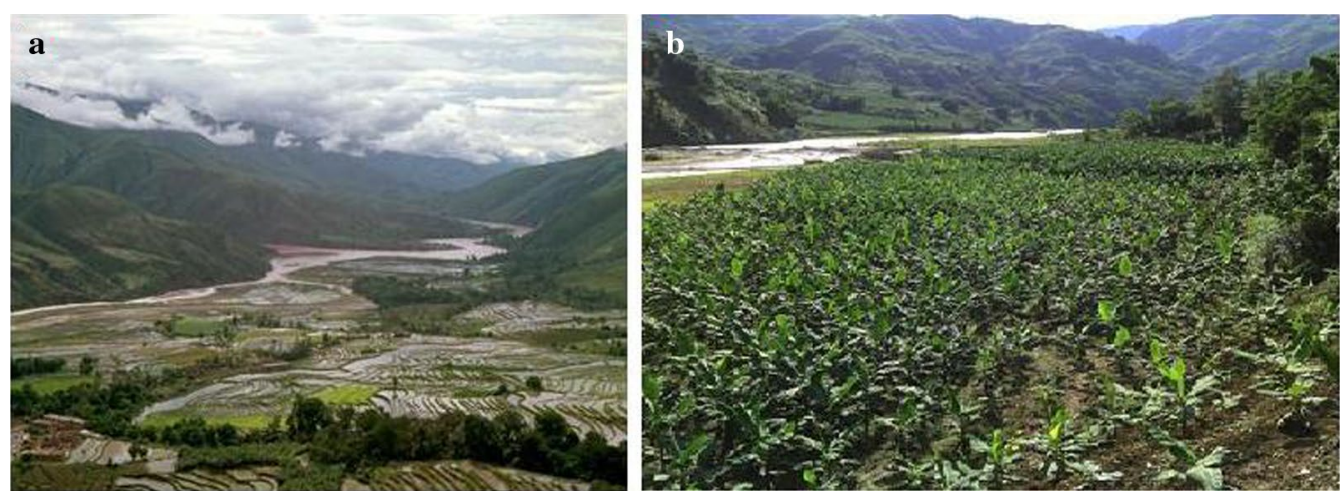

Fig. 2 Changed breeding environment for mosquito larvae due to growing bananas

who managed technical officers, and technical officers trained, guided and managed CHWs who trained, guided and managed VMCWs. One VMCW was in charge of five to ten households to administer drugs and spray insecticides. Malaria investigation and control activities were initiated in the winter of 1952. Two treatment methods were utilized: (1) presumptive treatment was given to people with enlarged spleens and malaria attack episodes in prior 6 months; (2) intermittent preventive treatment (IPT), once a week, was administered to others. Methods for vector control were treatment of larval breeding sites with insecticides in the low-transmission dry season from December to April, and indoor residual spraying (IRS) in the high-transmission rainy season from May to November; in addition, community mobilization was conducted for environmental management. During those years of low supplies, drugs and insecticides were used as long as they were available. Occasionally obtainable drugs were quinacrine hydrochloride, quinine sulfate, paludrine and/or plasmoquine. Obtainable insecticides were dichlorodiphenyltrichloroethane (DDT) or hexachlorocyolohexane (C6H6C6). These interventions reduced AMI from 358.62 per 1000 person-years $(89.32 \%$ Plasmodium falciparum of cases) in 1953 to 5.69 per 1000 person-years in 1960 (Table 1; Fig. 3).

1963-1977 In Hekou County in October 1963 the MCS became the Anti-epidemic Station (AES). This was a formal system of primary health care services comprising of three levels of county hospital and AES, township hospitals and village health stations for communicable diseases. The system conducted vector control and parasite treatment regularly, and radical cure treatment in lowtransmission seasons. Chloroquine and pamaquine were introduced for malaria treatment in this period. However, anti-malarial efforts were halted by the Great Cultural Revolution from 1966 to 1976. The AES was combined into Hekou County Hospital in 1968, and then detached from the hospital in 1971. This led to under-reporting of malaria; no malaria was reported in 1969 (Table 1; Fig. 3).
1978-2002 A policy of reform and stimulation of economic activities and population movement challenged the public health system. Internal and transnational population migration increased transmission and the spread of malaria. Less attention was paid by governments, and health staff, including CHWs, left for better economic income, which led to continued under-reporting of malaria. When a malaria epidemic broke out in 1987: AMI increased to 34.41 per 1000 person-years and five malaria-related deaths in the year; Honghe Prefecture had the highest number of malaria cases among 17 prefectures in Yunnan Province. Ultimately, deterioration of the malaria situation brought a political will to malaria control. Hehong Prefecture Government invested enough funding for anti-malarial drugs and insecticides. Additionally, artemisinin was registered in China in 1986. Introduction of artemisinin saved the life in control of the epidemic, and then oral and injective artemisinin monotherapy was recommended as the first line drugs for treatment of $P$. falciprum malaria and artemisinin-based combination therapy (ACTs) as the second line treatment in China. By 2002, AMI was lowered to fewer than one per 1000 person-years (Table 1; Fig. 3).

2003-2009 The Chinese government gave a stronger political commitment to public health after the epidemic of severe acute respiratory syndrome (SARS) in 2003. The Hekou County AES turned into Hekou County CDC. Malaria vector control, surveillance and treatment interventions were strengthened across the county. In addition, the Global Fund to Fight AIDS, Tuberculosis and Malaria (GFATM) grants strengthened core interventions. Intensive effort was made to seek and treat malaria to reduce under-reporting. In 2008, a cross-sectional survey screened 3900 residents by microscopy from 15 originally hyperendemic villages, in which no parasite carrier was detected. By 2008 , only 16 malaria cases were reported, and the AMI was lowered to 0.18 per 1000 person-years (Table 1; Fig. 2). 
Table 1 Historical record of malaria burden and interventions in Hekou County, Hehong (Red River) Prefecture, Yunnan Province, China from 1901 to 2015

\begin{tabular}{|c|c|c|c|}
\hline Year & Reporters & Description of malaria burden and interventions & Data resources \\
\hline 1901 to 1907 & Sheng Zuyan & $\begin{array}{l}\text { French Indo-China Railway Construction Co started railway con- } \\
\text { struction in Yunnan in 2001. Sheng, an officer from Chinese Qing } \\
\text { Dynasty Government reported in 1907 "Based on inspection to } \\
\text { construction of the railway line, at least 60,000-70,000 workers } \\
\text { died of malaria, hungry and violence" }\end{array}$ & $\begin{array}{l}\text { The report to Emperor } \\
\text { Guangxu of the Qing } \\
\text { Dynasty }\end{array}$ \\
\hline 1910 & $\begin{array}{l}\text { French Indo-China Railway } \\
\text { Construction Co }\end{array}$ & $\begin{array}{l}\text { During construction of Yunnan railway, 12,000 deaths, } 80 \text { of those } \\
\text { fatalities French }\end{array}$ & Manual of Yunnan Railway Line \\
\hline 1910 & Archives of Yunnan Province & $\begin{array}{l}\text { From } 2004 \text { to 2010, about 300,000 workers were recruited from } \\
\text { Yunnan, Guangdong and Sichuan Province to build Yunnan-Viet- } \\
\text { nam Railway, 60,000-70,000 deaths, most due to malaria }\end{array}$ & $\begin{array}{l}\text { Beginning and ending of Yun- } \\
\text { nan-Vietnam Railway }\end{array}$ \\
\hline 1917 & Hekou Anti-epidemic Station & $\begin{array}{l}\text { A puppet show team had } 24 \text { actors and actress, } 23 \text { fatalities due to } \\
\text { malaria }\end{array}$ & Archives of Hekou County \\
\hline 1940 & $\begin{array}{l}\text { Hekou Anti-epidemic Station. } \\
\text { Yang et al. }\end{array}$ & $\begin{array}{l}\text { A malaria outbreak in Hekou Town with a population of } 3000 \text { : } \\
\text { about } 20 \text { people died each day, total } 851 \text { deaths in 1940. There } \\
\text { were } 120 \text { soldiers of Kuomintang Army and } 13 \text { soldiers survived. } \\
\text { In 1940, a cross-sectional survey conducted by Dr. Zheng Zuyou } \\
\text { documented } 18.18 \% \text { parasite prevalence and } 47.30 \% \text { enlarged } \\
\text { spleen rate }\end{array}$ & $\begin{array}{l}\text { Archives of Hekou County. } \\
\text { Yunnan Malaria }\end{array}$ \\
\hline 1944 & Hekou Anti-epidemic Station & $\begin{array}{l}\text { In 1944, a team of Kuomintang Army settled in Hekou County, one } \\
\text { half of them died associated with malaria }\end{array}$ & Archives of Hekou County \\
\hline 1949 & Hekou Anti-epidemic Station & $\begin{array}{l}496 \text { of } 614 \text { inhabitants from } 123 \text { families died in four villages } \\
\text { (Yaoshan Feihui, Mali, Shibanzhai, Dazhai), none survived in } 19 \\
\text { households in a malaria outbreak }\end{array}$ & Archives of Hekou County \\
\hline 1952 & Hekou Anti-epidemic Station & $\begin{array}{l}\text { Establishment of malaria control system, initiation of control } \\
\text { interventions }\end{array}$ & Archives of Hekou County \\
\hline 1953 & $\begin{array}{l}\text { 3rd Military Malaria Control Team } \\
\text { of Yunnan Province }\end{array}$ & $\begin{array}{l}6591 \text { malaria cases reported, AMI } 358.62 \text { per } 1000 \text { person-years, } \\
89.32 \% \text { of these cases were P. falciparum }\end{array}$ & Archives of Hekou County \\
\hline 1963 & $\begin{array}{l}\text { Hekou County Anti-epidemic } \\
\text { Station }\end{array}$ & $\begin{array}{l}\text { Hekou Anti-epidemic Station was established for malaria control. } \\
288 \text { malaria cases reported, AMI reduced to } 8.02 \text { per } 1000 \\
\text { person-years }\end{array}$ & Archives of Hekou County \\
\hline 1969 & $\begin{array}{l}\text { Hekou County Anti-epidemic } \\
\text { Station }\end{array}$ & $\begin{array}{l}\text { County Anti-epidemic Station combined into County Hospital. No } \\
\text { malaria case could be reported because of Great Cultural Revolu- } \\
\text { tion Campaign }\end{array}$ & Archives of Hekou County \\
\hline 1987 & $\begin{array}{l}\text { Hekou County Anti-epidemic } \\
\text { Station }\end{array}$ & $\begin{array}{l}\text { A malaria epidemic in June 1987, } 2331 \text { malaria cases, AMI } 34.41 \text { per } \\
1000 \text { person-years and } 5 \text { deaths. Outpatients of Xinjie Township } \\
\text { Hospital treated } 1531 \text { malaria cases and malaria accounted for } \\
32.81 \% \text { hospitalization patients from June to December. A cross- } \\
\text { sectional study documented } 43.17 \% \text { (180/417) of slide positivity } \\
\text { rate, } 87.78 \% \text { (158/180) of } P \text {. vivax, } 11.67 \% \text { (21/180) of } P \text {. falciparum, } \\
\text { 0.56\% (1/180) of mixed infection among febrile patients, and } \\
\text { 10.03\% (258/2570) parasite prevalence among residents. Ento- } \\
\text { mological investigation collected } 539 \text { anopheline mosquitoes, } \\
\text { including } 244 \text { (45.3\%) An. minimus (local primary vector), man- } \\
\text { biting rate was } 81.3 \text { mosquitoes per person-night }\end{array}$ & Archives of Hekou CDC \\
\hline 1988 & $\begin{array}{l}\text { Hekou County Anti-epidemic } \\
\text { Station }\end{array}$ & $\begin{array}{l}\text { Intensive efforts were undertaken to control the outbreaks in } \\
\text { 1987. MDA to 10,227 inhabitants for radical cures from January } \\
\text { to March (dry and low transmission season). Chemoprophylaxis } \\
\text { delivered to 22,091 local residents and } 2085 \text { migrants from June } \\
\text { to November (wet and high transmission season). } 726,868 \mathrm{~m}^{2} \text { of } \\
\text { indoor wall surfaces sprayed with DDT and } 6262 \text { bed nets treated } \\
\text { with deltamethrin. Malaria cases reduced to } 1018 \text { and no fatality. } \\
\text { AMl reduced to } 14.78 \text { per } 1000 \text { person-years }\end{array}$ & Archives of Hekou CDC \\
\hline 1995 to 2002 & $\begin{array}{l}\text { Hekou County Anti-epidemic } \\
\text { Station }\end{array}$ & $\begin{array}{l}\text { As a result of the epidemic, Hehong Prefecture top AMI among } 17 \\
\text { prefectures in Yunnan Province. Government gave special atten- } \\
\text { tion to malaria and invested funding for anti-malarial drugs and } \\
\text { insecticides. By 2002, number of malaria patients reduced to } 75 \\
\text { cases and AMI to } 0.98 \text { per } 1000 \text { person-years }\end{array}$ & Archives of Hekou CDC \\
\hline
\end{tabular}


Table 1 continued

\begin{tabular}{|c|c|c|c|}
\hline Year & Reporters & Description of malaria burden and interventions & Data resources \\
\hline $\begin{array}{c}\text { Jan } 2003 \text { to } \\
\text { Jun } 2010\end{array}$ & Hekou County CDC & $\begin{array}{l}\text { From } 2003 \text { to 2008, under support of the first round of GFATM } \\
\text { for malaria, 19,607 febrile cases diagnosed by microscopy, } 427 \\
\text { malaria cases confirmed and treated with anti-malarial drugs, } \\
4963 \text { courses of presumptive treatments delivered to suspected } \\
\text { malaria patients, } 1313 \text { courses of radical cure treatments (RCT) } \\
\text { to people with malaria attack history last year, } 4414 \text { courses of } \\
\text { RCT to hyperendemic communities, 13,619 courses of preven- } \\
\text { tive treatments to people at high risk, IRS conducted for 52,635 } \\
\text { households in } 1316 \text { villages and } 8466 \text { bed nets impregnated } \\
\text { with insecticide } \\
\text { From } 2007 \text { to June } 2010, \text { under support of the fifth round of GFATM } \\
\text { for malaria, } 23,688 \text { febrile cases were diagnosed by micros- } \\
\text { copy, } 91 \text { malaria cases confirmed and treated, } 7278 \text { courses of } \\
\text { presumptive treatments given to suspected malaria patients, } \\
\text { 1523 courses of RCT to people with malaria attack history last } \\
\text { year, } 4529 \text { courses of RCT to hyperendemic communities, } 4003 \\
\text { courses of preventive treatments to people at high risk, IRS con- } \\
\text { ducted for } 14,784 \text { households in } 464 \text { villages and 10,886 bed nets } \\
\text { impregnated with insecticide. } 16 \text { malaria cases were detected } \\
\text { by } 2008\end{array}$ & $\begin{array}{l}\text { Archives of Hekou County } \\
\text { CDC }\end{array}$ \\
\hline $\begin{array}{r}\text { Jul } 2010 \text { to } \\
\text { Dec } 2015\end{array}$ & Hekou County CDC & $\begin{array}{l}\text { Efforts were taken in surveillance, focus investigation and rapid } \\
\text { response since malaria elimination action launched on } 1 \text { July, } \\
\text { 2010. } 10 \text { microscopy stations were strengthened, 13,943 and } \\
2309 \text { febrile cases were test by microscopy and RDT respectively, } \\
\text { the foci of } 4 \text { confirmed malaria (2 P. vivax and } 1 \text { P. falciparum) and } \\
780 \text { suspected malaria cases investigated, and active detec- } \\
\text { tions conducted in } 85 \text { originally hyperendemic villages. Health } \\
\text { education and social mobilization promote treatment-seeking } \\
\text { and use of preventive measures. Mechanism of collaboration and } \\
\text { information exchange established between Hekou County of } \\
\text { China and Lao Cai Province of Vietnam. } 300 \text { suspected Vietnam- } \\
\text { ese malaria cases tested by microscopy and one P. vivax cases } \\
\text { detected treated. Meanwhile, a cross-sectional study tested } 400 \\
\text { Vietnamese inhabitants for malaria. Vector mosquitoes were } \\
\text { investigated in } 2 \text { Vietnamese villages. The last local infection was } \\
\text { vivax malaria detected from a } 76 \text { years old man on } 22 \text { June, } 2011 . \\
\text { From then on, there was no indigenous case. Yunnan Province } \\
\text { certified Hekou County malaria free in November, } 2015\end{array}$ & $\begin{array}{l}\text { Archives of Hekou County } \\
\text { CDC }\end{array}$ \\
\hline
\end{tabular}

\section{Elimination, 2010-2015}

China re-oriented its malaria programme from control to elimination in July 2010. In order to look for infections and to interrupt transmission, the focus was shifted from high levels of coverage of interventions to an emphasis on completeness and timeliness of activities. Methodology of reactive case detection (RACD) was used in eliminating malaria. The '1-3-7' approach was introduced for guiding and monitoring case reports, investigation and response, respectively: reporting of malaria cases within 1 day $(24 \mathrm{~h})$, their confirmation and investigation within 3 days, and the appropriate public health response to prevent further transmission within 7 days. Since 2012 no indigenous malaria infections have been detected in Hekou. Only one imported malaria case was found in 2012 and 2013 respectively, and no any malaria case in 2014 and 2015. Yunnan Provincial Health and Family Planning Commission (HFPC) received an application for evaluating malaria elimination from Honghe Prefecture HFPC in September, 2015. A team comprising experts of health system and information management, surveillance, monitoring and evaluation, laboratory diagnosis quality assurance, epidemiology and entomology, conducted an evaluation of malaria elimination based on "China National Guidelines for Malaria Elimination Evaluation and Certification". Yunnan Province certified the county malaria-free in 4 November, 2015 (Table 1; Fig. 3).

\section{Relationship between AMI and socio economic development and environmental change}

Results of linear regression analysis indicated that AMI was negatively associated with national GDP (NGDP), national urbanization rate (NUR) and BPA. Correlation coefficients $(\mathrm{R})$ were $-0.6845(95 \% \mathrm{CI}-0.7978,-0.6845)$ for NGDP, $-0.7014(-0.8093,-0.7014)$ for NUR and $-0.5563(-0.7147,-0.3437)$ for BPA (Table 2). Analogous results were obtained for Yunnan Provincial GDP (YNGDP) and Yunnan Provincial urbanization rate (YNUR) (Table 2). Years 2000-2015 was a period of rapid socio-economic development and environmental change 


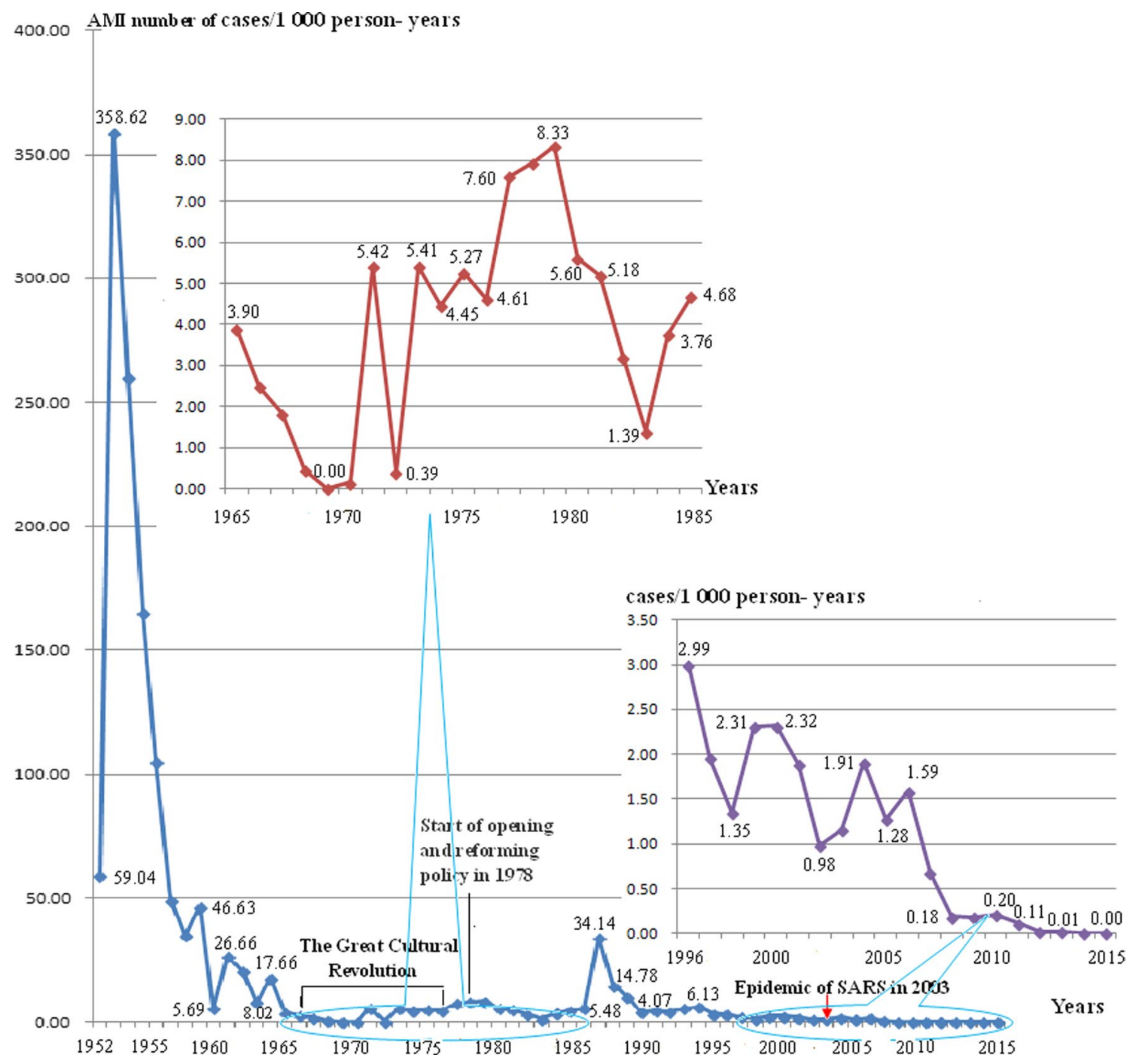

Fig. 3 Annual malaria incidence (AMI) in Hekou County from 1952 to 2015

in China, and the data malaria cases was less biased than prior to 2000-2015. The relationship between AMI and these independent variables was more closely associated in this period (Fig. 4). When a bilinear regression analysis was conducted, $\mathrm{R}$ was $-0.9103(-0.9716,-0.7345)$ for NGDP and BPA, and $-0.9055(-0.9700,-0.7216)$ for NUR and BPA (Table 2). All these results show that the AMI had a negatively strong correlation with socio-economic development and environmental change.

\section{Discussion}

The purpose of the paper is to describe the malaria burden before 1951, the procedures from hyperendemicity to elimination of malaria for 64 years (1952-2015) and related socio-economic and environmental factors in a county on the China-Vietnam border, and discuss Hekou's experiences and lesson implication for global malaria eradication.

Stable political and social status is important for effective malaria interventions. Paper-based records and interviewees' descriptions showed that Hekou was part of the hyperendemic areas before the establishment of People's Republic of China. Malaria burden during Yunnan-Vietnam railway construction is one of the earliest highlighted records on malaria burden in China. In spite of the fatality difference in Chinese and French records, the two records document a heavy malaria burden (Table 1). In those war-ridden years, it was difficult to carry out effective malaria intervention. The new government of China put people's wellbeing 
Table 2 Results of linear regression analysis between annual malaria incidence (AMI) and independent variables in Hekou, Yunnan Province, China

\begin{tabular}{|c|c|c|c|}
\hline Relationship between & $\mathrm{R}(95 \% \mathrm{Cl})$ & $\mathrm{R}^{2}(95 \% \mathrm{Cl})$ & $P$ value \\
\hline \multicolumn{4}{|l|}{$1952-2013$} \\
\hline AMI and NGDP & $-0.6845(-0.7978,-0.6845)$ & $0.4685(0.4685,0.6366)$ & $<0.0001$ \\
\hline AMI and NUR & $-0.7014(-0.8093,-0.7014)$ & $0.4919(0.4919,0.6550)$ & $<0.0001$ \\
\hline $\mathrm{AMI}$ and $\mathrm{YNGDP}$ & $-0.6802(-0.7949,-0.6802)$ & $0.4627(0.4627,0.6319)$ & $<0.0001$ \\
\hline AMI and YNUR & $-0.6892(-0.8011,-0.6892)$ & $0.4750(0.4750,0.6417)$ & $<0.0001$ \\
\hline \multicolumn{4}{|l|}{$1958-2013$} \\
\hline $\mathrm{AMI}$ and BPA & $-0.5563(-0.7147,-0.3437)$ & $0.3095(0.1181,0.5108)$ & $<0.0001$ \\
\hline \multicolumn{4}{|l|}{$2000-2013$} \\
\hline AMI and NGDP & $-0.8939(-0.9662,-0.6911)$ & $0.7990(0.4776,0.9336)$ & $<0.0001$ \\
\hline AMI and NUR & $-0.8770(-0.9630,-0.6479)$ & $0.7692(0.4198,0.9274)$ & $<0.0001$ \\
\hline $\mathrm{AMI}$ and $\mathrm{YNGDP}$ & $-0.8933(-0.9660,-0.6895)$ & $0.7980(0.4755,0.9332)$ & $<0.0001$ \\
\hline AMI and YNUR & $-0.8919(-0.9656,-0.6859)$ & $0.7954(0.4705,0.9323)$ & $<0.0001$ \\
\hline $\mathrm{AMI}$ and BPA & $-0.8587(-0.9544,-0.6027)$ & $0.7374(0.3633,0.9109)$ & $<0.0001$ \\
\hline AMI and NGDP with BPA & $-0.9103(-0.9716,-0.7345)$ & $0.8286(0.5394,0.9440)$ & $<0.0001$ \\
\hline AMI and NUR with BPA & $-0.9055(-0.9700,-0.7216)$ & $0.8199(0.5207,0.9410)$ & $<0.0001$ \\
\hline
\end{tabular}

$R$ correlation coefficient, $R^{2}$ coefficient of determination, $95 \%$ CI 95\% confidence interval, NGDP national gross domestic product, NUR national urbanization rate, YNGDP Yunnan Provincial gross domestic product, YNUR Yunnan Provincial urbanization rate, BPA banana planting area

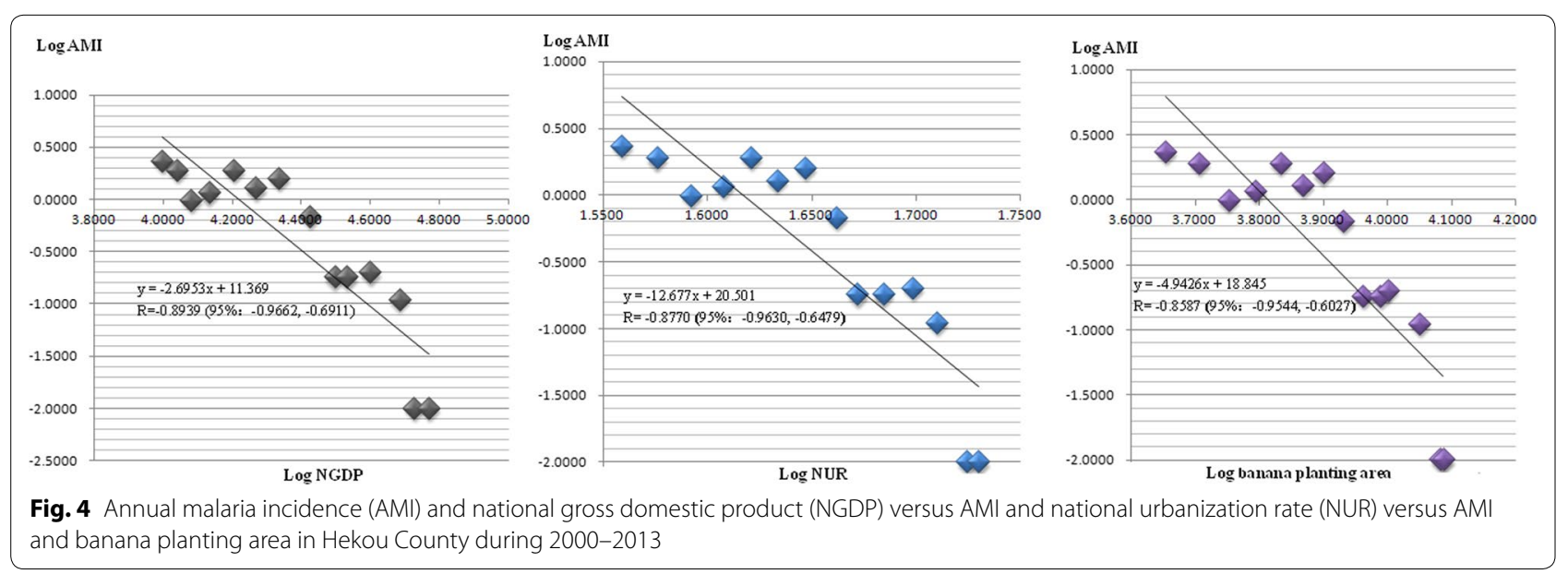

in an important position and gave political commitment to malaria control. In the context of shortage of armamentarium, medicine and human resources, the effective collaboration between military and civil medicine sectors set up an effective system for malaria prevention and treatment in a short time, which reduced malaria burden significantly (Fig. 3). Importantly, the system of malaria control expanded into a primary health care system (PHCS). Similarly, malaria elimination in Sri Lanka documented the importance of political will for malaria control. Strong governmental commitment eliminated malaria in this underdeveloped country [21].
The PHCS played important role in the history of malaria control. The PHCS in rural areas was called rural cooperative medical system (RCMS) that was developed under collective financing and public support from the People's Commune. Health personnel and facilities were organized on a three-tier system (county, commune and village). 'Barefoot doctors' were the backbone of the RCMS and their emphasis was on prevention. They were trained in both therapeutics and prophylaxis, both western and traditional Chinese medicine. In addition, women barefoot doctors learn midwifery, maternal and childcare [22]. The PHCS provided basic health services to one-fifth of the world's population [23], and improved 
communicable disease control, including malaria, by using 'mass mobilization', public education, and auxiliary personnel training. The RCMS that was operated by the villagers on a collective and mutual aid basis effectively maintained activities of malaria prevention and treatment. The villagers received free medical care in the cooperative health stations [24].

Malaria epidemics occurred in many other parts of Yunnan Province where the activities of RCMS were sharply curtailed during the great culture revolution (Fig. 3). From 1968 to 1977, a population of 1,877,539 was affected by malaria epidemic in Yunnan alone and 1142 people died of malaria-related diseases; 409,117 malaria cases, 217.9 per 1000 person-years AMI and 26.11\% $(40,383 / 154,700)$ parasite prevalence was reported in the epidemic [11]. However, the RCMS provided malaria treatment and prevention, ensuring low and stable malaria prevalence in Hekou even though the county's anti-epidemic station was combined into the county hospital and unable to fully collect and report on malaria cases.

Strong public health system is basis of for malaria control and elimination. China's post-1978 economic reforms in agricultural production and public financing diminished collective financing and public support for the RCMS. The continuing decline in the RCMS seriously affected healthcare: the number of barefoot doctors per capita diminished; most barefoot doctors forewent continuing education; there was an increase in the financial burden borne by farmers; and hospitals experienced financial problems. With the collapse of RCMS financing, many barefoot doctors created private practices, charging patients for service and selling drugs $[25,26]$. Accumulative impact of economic reforms contributed to the malaria epidemic in 1987. The epidemic and increasing malaria incidence attracted the attention of local government to invest for drugs and insecticides. However, financing and personnel problems in healthcare were not solved until after the epidemic of SARS in 2003. The epidemic of SARS urged a strong commitment from central government to public health, including financing and coordinating a national malaria control and elimination programme. Meanwhile, international investment (20032012) from the GFATM accelerated malaria control and elimination in China (Table 1 ).

High access of population to core interventions is crucial for effective control and elimination of malaria. During 1950-1960s when resources were short, the malaria burden reduced dramatically and put Hekou into pre-elimination stage. This is resulted from the high access of population to treatment and vector measures. From 2003, continuously high intervention moved it from pre-elimination into elimination
(Table 1; Fig. 3). In spite of facing challenges today, such as resistance of anti-malarial drugs and insecticides [2], and the difficulty of finding a radical cure of vivax malaria [27], enough intervention could be effective. When five of the six GMS countries (all except China) reported artemisinin resistance of $P$. falciparum [28], the high coverage of intervention dramatically reduced the malaria burden [9], while drug sensitivity of malaria parasites has not changed significantly along the China-Myanmar border [29, 30].

Collaboration in prevention and control of crossborder malaria with neighbouring countries, and reinforcement of early diagnosis and prompt treatment also contribute border malaria control and elimination. One of the major obstacles to achieving malaria elimination is movement across international borders. Strengthening surveillance activities for rapid identification of importation or re-introduction of malaria is essential to address the movement of malaria [10]. During American and Vietnam conflict from 1955 to 1975, China gave a full support to Vietnam for malaria control. The collaboration might contribute a stable malaria situation in Hekou County in the time. In 2010, collaboration and information exchange mechanism, including annual meeting, routine information exchange, migrant management was again established between China Hekou County and Vietnam Lao Cai Province for border malaria surveillance and control (Table 1) [31]. That overall incidence of malaria is low in Vietnam, where the most affected are the central and south central hilly and mountainous areas, and malaria transmission is interrupted in northern provinces [32, 33], would also benefit malaria elimination of Hekou County on the China-Vietnam border.

Malaria is associated with socio-economic development and environmental Change as well as effective interventions as documented in Hainan Province of China [34]. The close relationship between AMI and NGDP and NUR documented that facilitated malaria elimination in Hekou (Table 2; Fig. 4). Growth of GDP provided assurance of financial investment for malaria control and urbanization. Increasing production has been changing the biophysical environment. Increasing banana-growing areas reduce mosquito-breeding sites, and the use of insecticides kills mosquitoes directly. This is showed by the strong correlation between the AMI and BPA, especially during 2000-2013 when the BPA were increasing rapidly (Table 2; Fig. 4). Results of bilinear regression analysis indicate that socio-economic development and biophysical environment changes are associated with reduction of burden and elimination of malaria, as well as interventions, in Hekou County (Table 2; Fig. 4). 
Four limitations exist in this study. Firstly, data of individual interventions and associated reduction of the malaria burden are not available, population level figures and qualitative descriptions are used as replacements. The results on malaria burden before 1951 was descriptive and were based on fragmentary descriptions. Similar limitation is that an ecological study existed in the study that was not able to prove impact given the lack of a control [35], only suggestive evidences can be provided. Secondly, from 1966 to 1986, malaria cases might have been under-reported, so that the true malaria situation cannot be documented (Table 1; Fig. 3). Thirdly, although the single and bilinear regression analysis documents that socio-economic development and environmental change contributes to reduced malaria burden and elimination, it cannot be used to document quantitative contributions from control interventions because of lack of sequential data of interventions. Fourthly, annually sequential data of GDP and urbanization for Hekou County are not available, so the national and provincial data are used for the linear regression analysis. However, Hekou is an underdeveloped border county in China so that investments from upper government, such as national and provincial governments, are the main resource for regional socio-economic development as well as malaria control. From this view, the national and provincial data for the analysis would work equally as the data from the county level.

\section{Conclusion}

From the experiences of Hekou, five implications might be useful for global malaria eradication. First, political commitment and governmental executive ability are pivotal for malaria control and elimination. Under strong governmental commitment many socio-economic constraints (such as financial and human resources) could be overcome and healthcare systems can be strengthened. Second, national health orientations and policies can dramatically affect efficacy and interventions of malaria control. Third, integration of primary healthcare together with malaria control contributes to sustainability of effective malaria control and surveillance. Fourth, high coverage of malaria intervention and population access to the intervention is crucial at any stage of malaria control and elimination. Fifth, malaria incidence is affected by socio-economic development, biophysical environment change, and malaria situation of neighbouring countries or regions. Multifaceted factors, including political commitment, effective interventions, socio-economic development, and changing biophysical environment work together for the elimination of malaria in Hekou (Additional file 1).

\section{Additional file}

Additional file 1. National gross domestic product (GDP) and urbanization rate (UR), Yunnan GDP and UR, Hekou's banana planting area and annual malaria incidence.

\section{Authors' contributions}

JWX and HL designed the study, developed the protocol, analysed and interpreted the data. JJL and WJW organized collection of the data. HPG, SWP, SML, and RHW collected the data. JWX and HL wrote the first draft of the paper. All authors read and approved the final manuscript.

\section{Author details \\ ${ }^{1}$ Yunnan Institute of Parasitic Diseases, Yunnan Provincial Centre of Malaria Research, Yunnan Provincial Key Laboratory of Vector-borne Diseases Control and Research, Puer 665000, China. ${ }^{2}$ Honghe Prefecture Centre for Disease Prevention and Control, Mengzi, China. ${ }^{3}$ Hekou County Centre for Disease Prevention and Control, Hekou, China.}

\section{Acknowledgements}

We thank Mr. Hongzhang Xu from College of Medicine, Biology and Environment, Australian National University for his comments and copyediting. We are grateful to colleagues from Yunnan Institute of Parasitic Disease, Honghe Prefecture Centre for Disease Prevention and Control and Hekou County Centre for Disease Prevention and Control for their assistance and collaboration in the investigation. The opinions expressed are those of the authors and do not necessarily reflect those of the above organizations.

\section{Competing interests}

The authors declare that they have no competing interests.

\section{Availability of data and materials}

Additional file 1: Data of malaria, socio-economic development and banana planting. The detailed data and materials are available in Yunnan Institute of Parasitic Diseases, Puer; Honghe Prefecture Centre for Disease Prevention and Control, Mengzi; Hekou County Centre for Disease Prevention and Control, Hekou. China.

\section{Consent for publication}

All authors of the manuscript have read and agreed to submit this manuscript. They are accountable for all aspects of the accuracy and integrity of the manuscript in accordance with ICMJE criteria.

\section{Ethics approval and consent to participate}

The study was a description and statistical analysis of data from malaria control and elimination programme. Data utilized were existing, aggregate and without personal identifiers so that subjects' consent to participate was unable to be indicated. Ethical approval for the study under project'Research of molecular basis of delayed asexual parasite clearance times in treatment of P. falciparum malaria with dihydroartemisinin-piperaquine in Yunnan and neighbouring areas of other countries' (Reference number: YIPD-EC-2016[01]) was granted by the Ethics Committees of the Yunnan Institute of Parasitic Diseases, China. As a part of this project, the Ethics Committees also approved the study to collect and analyse historical data of malaria burden and interventions.

\section{Funding}

Collection of data was supported by national malaria elimination programme of China. Data analysis and preparation of the manuscript were supported by the National Natural Science Foundation of China (NSFC/81673113).

Received: 28 November 2016 Accepted: 21 January 2017

Published online: 07 February 2017

References

1. WHO. Global technical strategy for malaria 2016-2030. Geneva: World Health Organization; 2015. 
2. WHO. World malaria report 2015. Geneva: World Health Organization; 2015.

3. WHO. Strategy for malaria elimination in the Greater Mekong Subregion: 2015-2030. Geneva: World Health Organization; 2015.

4. Xu JW, Liu H, Zhang Y, Guo XR, Wang JZ. Risk factors for border malaria in a malaria elimination setting: a retrospective case-control study in Yunnan, China. Am J Trop Med Hyg. 2015;92:546-51.

5. Xu JW, Liu H. The relationship of malaria between Chinese side and Myanmar's five special regions along China-Myanmar border: a linear regression analysis. Malar J. 2016;15:368.

6. Xu JW, Liu H. The challenges of malaria elimination in Yunnan Province, People's Republic of China. Southeast Asian J Trop Med Public Health. 2012:43:819-24

7. Cui L, Yan G, Sattabongkot J, Cao Y, Chen B, Chen X, et al. Malaria in the Greater Mekong Subregion: heterogeneity and complexity. Acta Trop. 2012;121:227-39.

8. Liu H, Xu JW, Yang HL, Li M, Sun CD, Yin YJ, et al. Investigation and control of a Plasmodium falciparum malaria outbreak in Shan Special Region II of Myanmar along the China-Myanmar Border from June to December 2014. Infect Dis Poverty. 2016:5:32

9. Xu JW, Li Y, Yang HL, Zhang J, Zhang ZX, Yang YM, et al. Malaria control along China-Myanmar Border during 2007-2013: an integrated impact evaluation. Infect Dis Poverty. 2016;5:75.

10. Wangdi K, Gatton ML, Kelly GC, Clements AC. Cross-border malaria: a major obstacle for malaria elimination. Adv Parasitol. 2015;89:79-107.

11. Yang HL, Zhou HN. Yunnan malaria (in Chinese). Kunming: Yunnan Science and Technology press; 2015. p. 101-3.

12. Ministry of Health in China. Chinese malaria elimination action plan (2010-2020). http://www.nhfpc.gov.cn/jkj/s5873/201005/f84f1c4b0f32420990d23b65a88e2d87.shtml. Accessed 25 Apr 2016.

13. Chen J, Xiao N. Chinese action towards global malaria eradication. Lancet. 2016;388:959.

14. Baidu. [Yao Autonomous County of Hekou] (in Chinese). http://baike. baidu.com/view/136518.htm.

15. Hii J, Rueda L. Malaria vectors in the Greater Mekong Subregion: Overview of malaria vectors and remaining challenges. Southeast Asian J Trop Med Public Health. 2013;44(Suppl 1):73-165 (discussion 306-7)

16. Dong XS. The malaria vectors and their ecology in Yunnan Province (in Chinese). Chin J Parasit Dis. 2000;13:144-7.

17. Yang W, Li Z, Lan Y. A nationwide web-based automated system for outbreak early detection and rapid response in China. Manila:WPSAR, World Health Organization Regional Office for the Western Pacific; 2011.

18. Xu JW, Xu QZ, Liu H, Zeng YR. Malaria treatment-seeking behaviour and related factors of Wa ethnic minority in Myanmar: a cross-sectional study. Malar J. 2012;11:417.
19. Xu JW, Liao YM, Liu H, Nie RH, Havumaki J. Use of bed nets and factors that influence bed net use among Jinuo ethnic minority in Southern China. PLoS ONE. 2014;9:e103780. doi:10.1371/journal.pone.0103780.

20. Bewick V, Cheek L, Ball J. Statistics review 7: correlation and regression. Crit Care. 2003:7:451-9. doi:10.1186/cc2401.

21. Senaratne R, Singh PK. Against the odds, Sri Lanka eliminates malaria. Lancet. 2016;388:1038-9.

22. Wen C. Barefoot doctors in China. Nurs Dig. 1975;3:26-8.

23. Taylor RB. Primary health care in the People's Republic of China. Postgrad Med. 1981;70:69-76.

24. Caros L. A view of medical care in China. J lowa Med Soc. 1982;72:15-7.

25. Hsiao WC. Transformation of health care in China. N Engl J Med. 1984:310:932-6.

26. Shi L. Health care in China: a rural-urban comparison after the socioeconomic reforms. Bull World Health Organ. 1993;71:723-36.

27. WHO. Control and elimination of Plasmodium vivax malaria: a technical brief. Geneva: World Health Organization; 2015.

28. WHO. Emergency response to artemisinin resistance in the Greater Mekong subregion: regional framework for action 2013-2015. Geneva: World Health Organization; 2014.

29. Liu H, Yang HL, Tang LH, Li XL, Huang F, Wang JZ, et al. Monitoring Plasmodium vivax chloroquine sensitivity along China-Myanmar border of Yunnan Province, China during 2008-2013. Malar J. 2014;13:364.

30. Liu H, Yang HL, Tang $L H$, Li XL, Huang F, Wang JZ, et al. In vivo monitoring of dihydroartemisinin-piperaquine sensitivity in Plasmodium falciparum along the China-Myanmar border of Yunnan Province, China during 2007-2013. Malar J. 2015;14:47.

31. Zhou H, Du L, Yang H, Zhang Z. Innovative decade of cross-border joint prevention and control project of malaria and dengue fever in Yunnan China-GMS areas (in Chinese). Kunming: Yunnan Science and Technology Press; 2016. p. 24.

32. Morillon M, Baudon D, Dai B. Malaria in Vietnam in 1996: brief synthesis of epidemiological data (in French). Med Trop. 1996;56:197-200.

33. Thanh PV, Hong NV, Van NV, Malderen CV, Obsomer V, Urgell AR, et al. Epidemiology of forest malaria in Central Vietnam: the hidden parasite reservoir. Malar J. 2015;14:86.

34. Wang SQ, Li YC, Zhang ZM, Wang GZ, Hu XM, Qualls W, et al. Prevention measures and socio-economic development result in a decrease in malaria in Hainan, China. Malar J. 2014;13:362.

35. Hsiang M, Hwang J, Tao A, Liu Y, Bennett A, Shanks GD, et al. Mass drug administration for the control and elimination of Plasmodium vivax malaria: an ecological study from Jiangsu province, China. Malar J. 2013;12:383.

\section{Submit your next manuscript to BioMed Central and we will help you at every step:}

- We accept pre-submission inquiries

- Our selector tool helps you to find the most relevant journal

- We provide round the clock customer support

- Convenient online submission

- Thorough peer review

- Inclusion in PubMed and all major indexing services

- Maximum visibility for your research

Submit your manuscript at www.biomedcentral.com/submit
BioMed Central 